\title{
Challenges in professional supervision: Current themes and models for practice
}

\author{
Liz Beddoe and Allyson Davys, 2016 \\ Jessica Kingsley Publishers, London, UK \\ ISBN 978-1-84905-4652, pp. 248, paperback, NZD50.00
}

$\mathrm{T}$ his latest text by Beddoe and Davys is designed to be read either as a companion to their previous work Best practice in professional supervision: A guide for the helping professions (Davys \& Beddoe, 2010) or as a stand-alone book. It is presented in two parts, the first part explores contemporary ideas and debates in professional supervision, and the second part examines supervision modes, models and skills. Beddoe and Davys state that their aim with this book is to explore the most recent work on supervision, rather than focussing on classical literature on the subject. The result is a very useful text which is likely to appeal to supervisors and practitioners across the helping professions.

Although I found the introduction quite academic and wondered if this would offputting to some readers, the body of the book is very readable, and several chapters contain tables, questions or vignettes which assist with understanding and make application of ideas accessible. Considering supervision through the lenses of personal survival, professional development and quality assurance is a helpful framework, and invites readers to consider the foci of their supervision approach.

The text is aimed at supervisors across professional groups, and incorporates crossprofessional material which is an interesting reading as well as widens the appeal of the book to a range of helping professionals. The book provides comprehensive coverage, presenting material useful for supervisors and academics. I was pleased to see the inclusion of chapters on group supervision, supervision of managers and on courageous conversations. The scope of the material used made me feel up-to-date on many current issues and approaches, as it is based on contemporary research and literature while acknowledging classic contributions.

That said, I was surprised at the omission of indigenous models - there is a chapter on culture, gender and belief in part one of the book which addresses culture from an ethnic and wider cultural perspective and indigenous models are mentioned, but not included in part two of the book. Similarly, I thought there could have been greater exploration of spirituality in supervision (given the literature on this topic), extending readers' understanding that this can include safe space and engagement, not only rituals and beliefs. In contrast, at times the comprehensive nature of the book felt overwhelming and the scope broad, and I was unsure if some of the material (such as that on the journey of a new manager) was too wide and not supervisionspecific enough. Despite this question of breadth, I acknowledge that it is important to understand such information as a supervisor and it is useful in supervision practice.

Beddoe and Davys convey the importance of supervisors being supervision trained rather than falling into the role through professional maturation. They emphasise the importance of reflective supervision for the professional development of the supervisee, and the ultimate benefit of the client. They are cognisant of the tensions experienced by both practitioners 
and supervisors, and aim to reduce these through reflective and reflexive practice encouraged in supervision. Their application of their Reflective Learning Model in group supervision is one such example of this, and in doing so it is easy to see how their model is applicable in many supervision settings.

The authors have presented an excellent book with much to offer a range of supervisors, in a variety of professions across the globe. It is a book that I imagine many supervisors will frequently consult.
Beddoe and Davys note that their preferred definition of supervision emphasises "critical reflection and learning which, in turn, leads to transformational practice" (p. 160). This definition encapsulates their hopes for supervision practice and which are promoted by the content of this book that is, critical reflection, learning and transformational practice.

\section{Reference}

Davys, A., \& Beddoe, L. (2010). Best practice in professional supervision: A guide for the helping professions. London, United Kingdom: Jessica Kingsley.

Reviewed by Leisa Moorhouse Contractor \& Educator, New Zealand 